ScIDice

\section{Prevalence and Associated Factors of Root Canal Treated Mandibular Anterior Teeth with and without Post Endodontic Crowns}

Research Article

Roghith Kannan ${ }^{1}$, Adimulapu Hima Sandeep $2^{*}$, Revathi Duraisamy ${ }^{3}$

${ }^{1}$ Saveetha Dental College and Hospitals, Saveetha Institute of Medical and Technical Sciences Saveetha University, Chennai-600077, Tamilnadu, India. ${ }^{2}$ Senior Lecturer, Department of Conservative Dentistry and Endodontics, Saveetha Dental College And Hospitals, Saveetha Institute Of Medical And Technical Sciences, Saveetha University, Chennai-600077, Tamilnadu, India.

${ }^{3}$ Senior Lecturer, Department of Prosthodontics, Saveetha Dental College and Hospitals, Saveetha Institute of Medical and Technical Sciences Saveetha University, Chennai-600077, Tamilnadu, India.

\title{
Abstract
}

Restoration is an integral part of post endodontic therapy. After root canal therapy the teeth are more susceptible to fracture than vital teeth and therefore the provision of a restoration helps in the longevity of the tooth. The main objective of this study is to know the frequency of root canal treated mandibular anteriors not treated with post endodontic full veneer restoration. The current study is an institutional based retrospective study performed by reviewing 885 cases that had undergone root canal therapy in relation to mandibular anteriors. A total of 50 subjects who underwent root canal treatment in relation to mandibular anteriors from 18 to 25 years of age group were selected for the study from a total of 885 subjects who had undergone root canal treatment in relation to mandibular anteriors. Patients reported to the clinic other than mandibular anterior root canal treatment and medically compromised patients were excluded. Once the data was obtained and verified with the help of photographs, it was statistically analyzed using SPSS by IBM version 20. From this current study, it was found that, out of 50 patients, $76 \%$ (38) males and $24 \%$ (12) females have undergone root canal treatment. The incidence of teeth that didn't go for post endodontic crown is $55.67 \%$ (54). Highest incidence in the tooth group that didn't go for post endodontic crown is $41,25.77 \%$ (25), 38\% (19) males had the highest incidence for not undergoing post endodontic restoration. The highest incidence of post endodontic crown was seen in both 31 and 41 with $12.37 \%$. Chi square test was done to associate between gender and post endodontic crown and tooth number and post endodontic crown for prognosis of the root canal treated teeth.

Keywords: Mandibular Anteriors; Post Endodontic Restoration; Root Canal Treatment.

\section{Introduction}

A root filled tooth is unlike a vital tooth due to the effect of endodontic treatment. It is thought that root canal treatment leads to weakening of the remaining tooth structure as a result of various factors like changes in tooth architecture, changes in proprioception, changes in the properties of dentin [1]. The effects are the same for both anterior and posterior teeth as only the consequences vary depending on the anatomical structure and loading patterns. It has been stated that root canal therapy saves the tooth, whereas the restoration reinstates the tooth as a functional member of the masticatory system and also enhances the aesthetic appearance [2]. In order to accomplish this goal, the restorative procedure should be primarily concerned with prevention of tooth fracture. After completion of the endodontic treatment, depending on the remaining natural tooth structure, placement of the coronal seal/crown is indicated [3]. This prevents contamination and microleakage thus enforcing adequate stability and structural durability to the root canal treated tooth. Hence a temporary or permanent restoration should be placed after root canal therapy $[4,5]$.

Over the years controversies over the variety of materials being used for the reinforcement of the endodontically treated teeth, especially over the use of crowns have been studied [6]. If an endodontically treated anterior tooth is to receive a crown, a post

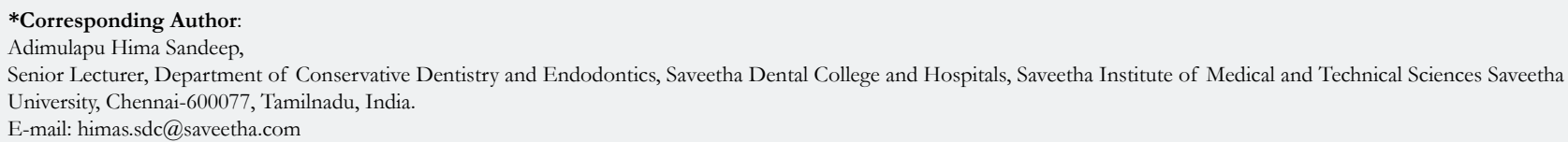

Citation: Roghith Kannan, Adimulapu Hima Sandeep, Revathi Duraisamy. Prevalence and Associated Factors of Root Canal Treated Mandibular Anterior Teeth with and without Post Endodontic Crowns. Int J Dentistry Oral Sci. 2019;S5:02:0016:87-91. doi: http://dx.doi.org/10.19070/2377-8075-SI02-050016

Copyright: Adimulapu Hima Sandeep ${ }^{2019}$. This is an open-access article distributed under the terms of the Creative Commons Attribution License, which permits unrestricted use, distribution and reproduction in any medium, provided the original author and source are credited. 
often is indicated. In most cases, the remaining coronal portion is quite thin after it has received root canal treatment and has been prepared for a crown [7]. Even though the successful root canal treatment promises to enhance the lifespan of the treated tooth in both structural and aesthetic aspects, there are few studies that suggest that the tooth with root canal procedures are not restored with permanent restoration after that root canal treatment are thought to be about two to four times weaker [8].

The presence of the remaining coronal tooth structure and the functional requirement of the teeth determine whether an anterior tooth requires a post [9]. A study done by Kruler CM et al showed that coronal coverage did significantly improve the rate of clinical success for anterior teeth [10]. When there is no functional (or) aesthetic requirement for a full coverage restoration, a post is not indicated. If a full coverage restoration is chosen however, the decision to place a post is dedicated by the amount of coronal remaining tooth structure present after the crown preparation is completed and the functional requirement of the restored tooth [11].

A systematic review done by Stavropoulou et al showed that root canal treated teeth covered with crowns have a higher long term survival rate than root canal treated teeth without crown coverage [12]. It is also suggested that saving the natural tooth requires both excellent endodontic treatment along with follow up of a restorative treatment in order to increase the longevity of the tooth [13]. The restoration of the endodontically treated teeth is a topic that is extensively studied and yet remains controversial from many perspectives. The aim of this study was to evaluate the frequency of root canal treated mandibular anteriors not treated with post endodontic full veneer restoration in patients under 25 years of age in our institution.

\section{Materials and Methods}

\section{Study Setting}

The current study is an institutional based retrospective study performed at a private dental college.

\section{Ethical approval}

The necessary approvals were obtained from the Institutional Ethical committee - SDC/SIHEC/2020/DIASDATA/0619-0320.

\section{Data Collection and Tabulation}

All the case records and treatment records were obtained from the patient management software and the data collected was cross verified by an examiner to avoid any missing case records. A total of 885 case sheets were verified for root canal treatment in relation to mandibular anteriors. Out of 885 subjects, 50 subjects who underwent root canal treatment in relation to mandibular anteriors under 25 years of age were chosen carefully verifying the data and history. All the data collected was formatted and tabulated using Microsoft Excel (Version - 2020). The dependent variable was root canal treated mandibular anteriors from 18 to 25 years of age group.

\section{Inclusion criteria}

The Inclusion criteria included patients undergoing root canal treatment in relation to mandibular anteriors from 18 to 25 years of age group.

\section{Exclusion criteria}

The exclusion criteria was missing or incomplete data and it also eliminated cases that were not approved by the concerned faculty in the hospital.

\section{Statistical analysis}

The statistical analysis was performed using IBM SPSS (Version - 24). Chi square test was done, to associate between gender and post endodontic crown for prognosis of the root canal treated teeth.

\section{Results and Discussion}

In the present study which included 50 patients, $76 \%$ (38) males and $24 \%$ (12) females have undergone root canal treatment (Figure 1). The most common teeth for root canal treatment was found to be 41 (25.77\%) followed by 31 (22.68\%), $42(21.65 \%)$, $32(15.46 \%)$ and the least being both 33 and 43 (7.22\%) (Figure 2). Out of 97 teeth which had undergone root canal treatment, post endodontic crown had been fabricated and inserted in 43 mandibular anteriors (44.3\%) and the remaining 54 (55.7\%) mandibular anteriors did not receive endodontic crowns (Figure 3). $38 \%$ of males and $10 \%$ of females had received crowns, $38 \%$ of males and $14 \%$ of females did not receive crowns (Figure 4) No significant association was seen between gender and practice of post endodontic crowns. Chi-square test was performed and was found to be statistically not significant $(\mathrm{p}=0.614 ; \mathrm{p}>0.05)$. $12.37 \%$ of root canal treated teeth in relation to 31 and 41 had received crowns, which was followed by $9.28 \%$ in $42,7.22 \%$ in $32,2.06 \%$ in 43 and the least being $1.03 \%$ in $33.13 .40 \%$ of root canal treated teeth in relation to 41 did not receive crowns, which was followed by $12.37 \%$ in $42,10.31 \%$ in $31,8.25 \%$ in $32,6.19 \%$ in 33 and the least being $5.15 \%$ in 43 . Results show the highest incidence of post endodontic crown was seen in both 31 and 41 with $12.37 \%$ compared to other teeth (Figure 5) Chi-square test was performed and was found to be statistically not significant $(\mathrm{p}$ $=0.496 ; \mathrm{p}>0.05)$.

Teeth with significant remaining natural tooth structure after endodontic treatment must be considered differently from those with extensive loss of tooth structure. When sufficient tooth structure is present to retain the core and crown, in such condition posts are not recommended. Success of endodontic treatment depends on the quality of the coronal restoration, which should provide the functional marginal seal and protect the remaining tooth structure $[11,12,14]$. In a study conducted by Sedgley et al, stated that anterior teeth must resist lateral and shearing types of forces and pulp chambers are too small for a post, depending on the remaining coronal structure, the placement of a post is decided [15]. In a study conducted by Naoum and Chandler [16], they found that there was no difference in the reinforcement of maxillary central incisors and mandibular cuspids without post. 
Figure 1. Bar graph depicts the frequency of males and females who had undergone root canal treatment in mandibular anteriors. $\mathrm{X}$ axis represents the gender of patients and $\mathrm{Y}$ axis shows the percentage of patients undergone root canal treatment. The results show the highest number subjected to root canal therapy was seen in males(blue) $76.00 \%$ compared to females(red) $24.00 \%$.

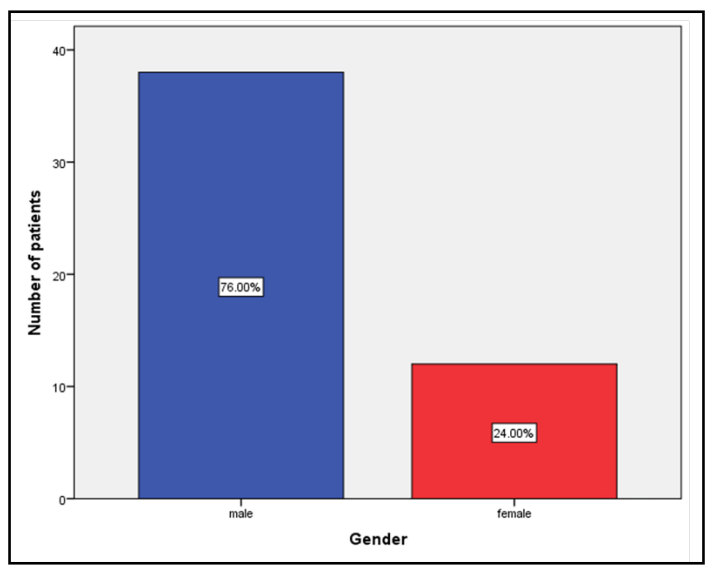

Figure 2. Bar graph depicts the frequency of various teeth involved in root canal treatment in mandibular anteriors. $\mathrm{X}$ axis shows the various teeth involved in root canal treatment where $Y$ axis shows the number of teeth. The results show the highest incidence of root canal treatment was seen in 41 with $25.7 \%$ compared to other teeth.

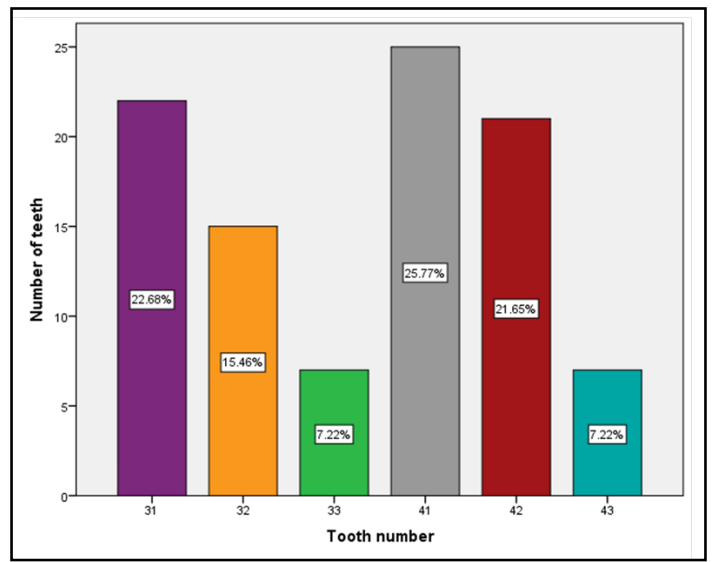

Figure 3. Bar graph depicts the frequency of incidence of post endodontic crown in patients who had undergone root canal treatment in mandibular anteriors. $X$ axis represents the post endodontic crown placement status of the patients in mandibular anteriors and $\mathrm{Y}$ axis represents the number of teeth. The results show that the incidence of post endodontic crown in mandibular anteriors was much less $(44.3 \%)$ when compared to teeth without a post endodontic crown (55.6\%).

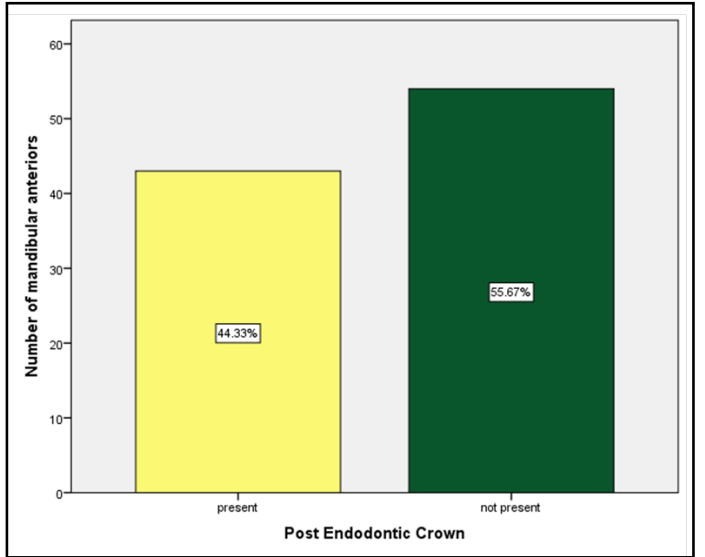

One of the causes of failure of endodontic treatments is an incomplete instrumentation or filling of all root canals. There are many factors which influence the fracture of an endodontically treated tooth. The risk of tooth fracture increases from the beginning of endodontic therapy, so effective temporary and final restorations are given. The primary concern is that of resistance form as the tooth must be able to resist both vertical and horizontal forces [17].

In the recent years prefabricated posts have become very popular. Overall fixed dental prosthesis bridges have significantly lower long term survival rates than teeth retained through RCT and restoration or those replaced using single implant crowns [18]. The 
Figure 4. Bar graph depicts the association of gender and incidence of post endodontic crown in mandibular anteriors. $\mathrm{X}$ axis represents the gender and $\mathrm{Y}$ axis shows the frequency of patients undergoing root canal treatment. Chi-square test was performed and there was no statistically significant association between gender and prevalence of post endodontic crown in mandibular anteriors (Pearson chi square value: 4.383 ; df: 9; p-value: $0.614>0.05$ ). The frequency of males who did not receive prosthesis were more than that of females.

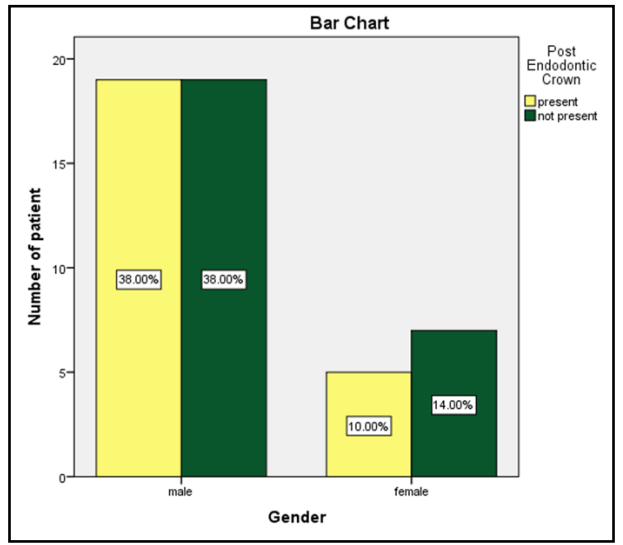

Figure 5. Bar graph depicts the association between various teeth with and without post endodontic crown in root canal treated mandibular anteriors. $X$ axis represents the various teeth involved and $Y$ axis shows the number of teeth. Chi-square test was performed and there was no statistically significant association between various teeth and prevalence of post endodontic crown in mandibular anteriors (Pearson chi square value: 4.383 ; df:5; p-value: $0.496>0.05$ ). Mandibular central incisors more commonly underwent post endodontic crown compared to others.

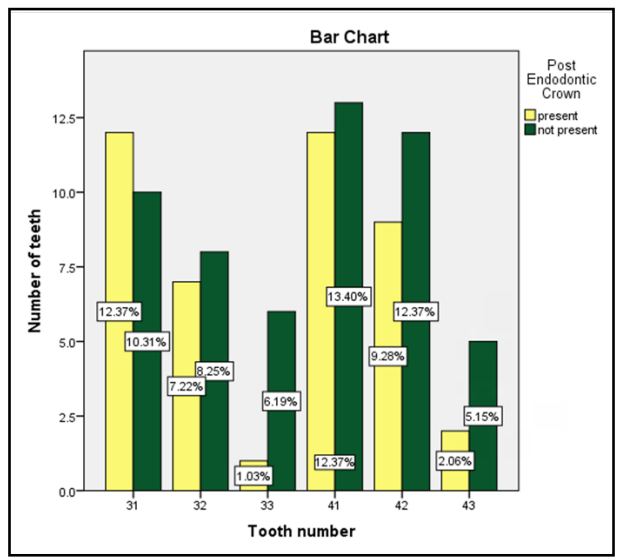

amount of remaining tooth structure is more important than any restorative strategy and the risks due to dental caries and periodontal disease must always be recognised in order to have a good prognosis.

The limitations of the present study include that it is single centered and has geographic limitations. The medical status of the patient was not considered with a sample size limitation as well. Further multi centered studies should be carried out with a larger sample size to create a standardized protocol for root canal therapy and post endodontic crowns. Previously our team had conducted numerous clinical trials [19-21], in vitro studies [22-26] and surveyed [27, 28] and reviewed various aspects of endodontics and conservative dentistry over the past five years [29-33]. Now we are focusing on retrospective studies, the idea for which has stemmed from the current interest in our community.

\section{Conclusion}

Within the limitations of the study, the prevalence of root canal treated mandibular anteriors with post endodontic crowns was $44.3 \%$, mandibular central incisors more commonly underwent post endodontic crown compared to other teeth and the associa- tion between gender and the practice of post endodontic crowns was not significant but males had undergone more number of crowns than females in the age group of 18 to 25 years. Root canal treated mandibular anterior teeth with sound tooth structure can be managed without full coverage restoration.

\section{Author Contribution}

Roghith Kannan carried out the retrospective study, collection and analysis of data and drafted the manuscript. Dr Adimulapu Hima Sandeep designed the study and participated in data analysis verification and drafting the manuscript. Dr Revathi D aided in supervision and appraisal of the manuscript.

\section{Acknowledgements}

We thank Saveetha Dental College and Hospitals, Chennai for access to the retrospective data.

\section{References}

[1]. Trabert KC, Caputo AA, Abou-Rass M. Tooth fracturel3-A comparison of endodontic and restorative treatments. J. Endod. 1978 Nov 1;4(11):341-5. 
[2]. Trope M, Ray Jr HL. Resistance to fracture of endodontically treated roots. Oral Surg Oral Med Oral Pathol. 1992 Jan 1;73(1):99-102.

[3]. Chugal NM, Clive JM, Spångberg LS. Endodontic treatment outcome: effect of the permanent restoration. Oral Surg Oral Med Oral Pathol and Endod. 2007 Oct 1;104(4):576-82.

[4]. Manohar MP, Sharma S. A survey of the knowledge, attitude, and awareness about the principal choice of intracanal medicaments among the general dental practitioners and nonendodontic specialists. Indian J Dent Res. 2018 Nov-Dec;29(6):716-720.Pubmed PMID: 30588997.

[5]. Dietschi D, Bouillaguet S, Sadan A. Restoration of the Endodontically Treated Tooth. Cohen's Pathways of the Pulp 2011; 777-807.

[6]. Ray HA, Trope M. Periapical status of endodontically treated teeth in relation to the technical quality of the root filling and the coronal restoration. Int Endod J. 1995 Jan;28(1):12-8.Pubmed PMID: 7642323

[7]. Sorensen JA, Martinoff JT. Intracoronal reinforcement and coronal coverage: a study of endodontically treated teeth. J Prosthet Dent. 1984 Jun;51(6):7804.Pubmed PMID: 6376780.

[8]. Weiger R, Axmann-Krcmar D, Löst C. Prognosis of conventional root canal treatment reconsidered. Endod Dent Traumatol. 1998 Feb;14(1):1-9.Pubmed PMID: 9643171.

[9]. Safavi KE, Dowden WE, Langeland K. Influence of delayed coronal permanent restoration on endodontic prognosis. Endod Dent Traumatol. 1987 Aug;3(4):187-91.Pubmed PMID: 3481569.

[10]. Wassell R, Nohl F, Steele J, Walls A, editors. Extra-coronal Restorations: Concepts and Clinical Application. Springer; 2018 Jul 31.

[11]. iqueira JF Jr, Rôças IN, Favieri A, Abad EC, Castro AJ, Gahyva SM. Bacterial leakage in coronally unsealed root canals obturated with 3 different techniques. Oral Surg Oral Med Oral Pathol Oral Radiol Endod. 2000 Nov;90(5):647-50.Pubmed PMID: 11077391

[12]. Stavropoulou AF, Koidis PT. A systematic review of single crowns on endodontically treated teeth. J. Dent. 2007 Oct 1;35(10):761-7.

[13]. Hussainy SN, Nasim I, Thomas T, Ranjan M. Clinical performance of resinmodified glass ionomer cement, flowable composite, and polyacid-modified resin composite in noncarious cervical lesions: One-year follow-up. J Conserv Dent. 2018 Sep-Oct;21(5):510-515.Pubmed PMID: 30294112.

[14]. Kishen A. Mechanisms and risk factors for fracture predilection in endodontically treated teeth. Endod Topics . 2006 Mar;13(1):57-83

[15]. Sedgley CM, Messer HH. Are endodontically treated teeth more brittle? J Endod. 1992 Jul;18(7):332-5.Pubmed PMID: 1402595.

[16]. Naoum HJ, Chandler NP. Temporization for endodontics. Int. Endod. J. 2002 Dec;35(12):964-78.

[17]. Henry PJ. Photoelastic analysis of post core restorations. Aust Dent J. 1977 Jun;22(3):157-9.Pubmed PMID: 337954

[18]. Torabinejad M, Anderson P, Bader J, Brown LJ, Chen LH, Goodacre CJ, et al. Outcomes of root canal treatment and restoration, implant-supported single crowns, fixed partial dentures, and extraction without replacement: a systematic review. J Prosthet Dent. 2007 Oct 1;98(4):285-311.

[19]. Ramamoorthi S, Nivedhitha MS, Divyanand MJ. Comparative evaluation of postoperative pain after using endodontic needle and EndoActivator dur- ing root canal irrigation: A randomised controlled trial. Aust Endod J. 2015 Aug;41(2):78-87.Pubmed PMID: 25195661.

[20]. Hussainy SN, Nasim I, Thomas T, Ranjan M. Clinical performance of resinmodified glass ionomer cement, flowable composite, and polyacid-modified resin composite in noncarious cervical lesions: One-year follow-up. J Conserv Dent. 2018 Sep-Oct;21(5):510-515.Pubmed PMID: 30294112.

[21]. Janani K, Palanivelu A, Sandhya R. Diagnostic accuracy of dental pulse oximeter with customized sensor holder, thermal test and electric pulp test for the evaluation of pulp vitality: an in vivo study. Braz. Dent. Sci. 2020 Jan 31;23(1):8-p.

[22]. Ramanathan S, Solete P. Cone-beam Computed Tomography Evaluation of Root Canal Preparation using Various Rotary Instruments: An in vitro Study. The J Contemp Dent Pract. 2015 Nov 1;16(11):869-72.

[23]. Siddique R, Sureshbabu NM, Somasundaram J, Jacob B, Selvam D. Qualitative and quantitative analysis of precipitate formation following interaction of chlorhexidine with sodium hypochlorite, neem, and tulsi. J Conserv Dent. 2019 Jan-Feb;22(1):40-47.Pubmed PMID: 30820081.

[24]. Rajendran R, Kunjusankaran RN, Sandhya R, Anilkumar A, Santhosh R, Patil SR. Comparative Evaluation of Remineralizing Potential of a Paste Containing Bioactive Glass and a Topical Cream Containing Casein Phosphopeptide-Amorphous Calcium Phosphate: An in Vitro Study. Pesqui. Bras. Odontopediatria Clín. Integr. 2019;19:1-10.

[25]. Teja KV, Ramesh S, Priya V. Regulation of matrix metalloproteinase-3 gene expression in inflammation: A molecular study. J. Conserv. Dent. 2018 Nov;21(6):592-596.

[26]. Nandakumar M, Nasim I. Comparative evaluation of grape seed and cranberry extracts in preventing enamel erosion: An optical emission spectrometric analysis. J Conserv Dent. 2018 Sep-Oct;21(5):516-520.Pubmed PMID: 30294113.

[27]. Jose J, Subbaiyan H. Different Treatment Modalities followed by Denta Practitioners for Ellis Class 2 Fracture-A Questionnaire-based Survey. Open Dent. J. 2020 Feb 18;14(1):59-65. h

[28]. Manohar MP, Sharma S. A survey of the knowledge, attitude, and awareness about the principal choice of intracanal medicaments among the genera dental practitioners and nonendodontic specialists. Indian J Dent Res. 2018 Nov-Dec;29(6):716-720.Pubmed PMID: 30588997.

[29]. Rajakeerthi R, Ms N. Natural Product as the Storage medium for an avulsed tooth-A Systematic Review. Cumhur. Dent. J. 2019;22(2):249-56.

[30]. Kumar D, Antony S. Calcified Canal and Negotiation-A Review. Res J Pharm Technol. 2018;11(8):3727-30.

[31]. Ravinthar K. Recent advancements in laminates and veneers in dentistry. Res J Pharm Technol. 2018;11(2):785-7.

[32]. Noor S. Chlorhexidine: Its properties and effects. Res J Pharm Technol. 2016;9(10):1755-60

[33]. Janani K, Palanivelu A, Sandhya R. Diagnostic accuracy of dental pulse oximeter with customized sensor holder, thermal test and electric pulp test for the evaluation of pulp vitality: an in vivo study. Br. Dent. J. 2020 Jan $31 ; 23(1): 8$. 